\title{
Quantifying sensitivity and uncertainty analysis of a new mathematical model for the evaluation of greenhouse gas emissions from membrane bioreactors
}

\author{
Giorgio Mannina*, Alida Cosenza \\ Dipartimento di Ingegneria Civile, Ambientale, Aerospaziale, dei Materiali-Università di Palermo, Viale delle Scienze, 90128 Palermo, Italy
}

\section{A R T I C L E I N F O}

\section{Article history:}

Received 8 April 2014

Received in revised form

28 September 2014

Accepted 4 October 2014

Available online 14 October 2014

\section{Keywords:}

Emissions

Model-based evaluation

Global warming

Wastewater treatment

\begin{abstract}
A B S T R A C T
A new mathematical model able to quantify greenhouse gas (GHG) emissions in terms of carbon dioxide $\left(\mathrm{CO}_{2}\right)$ and nitrous oxide $\left(\mathrm{N}_{2} \mathrm{O}\right)$ for a Membrane Bioreactor (MBR) is presented. The proposed mathematical model is of the Activated Sludge Model (ASM) family and takes into account simultaneously both biological and physical processes (e.g., membrane fouling). An analysis of the key factors and sources of uncertainty influencing GHG emissions is also presented. Specifically, the standardized regression coefficient, the Extended-FAST and a Monte Carlo based method are employed for assessing model factors which influence three performance indicators: effluent quality index, operational costs and GHGs. Model factors are classified as important, non-influential and interacting. The model is applied to a University Cape Town-MBR pilot plant which was object of an extensive field gathering campaign. The results reveal that model factors related to nitrogen transformation and membrane separation processes play a central role in the uncertainty of GHG estimation. Model factors that are associated with physical processes exhibit large first-order and total-order effects, which emphasises the importance of a holistic approach that jointly considers biological and physical processes. Furthermore, the membrane has a key role in GHG emissions as a result of the cake layer thickness which in turns influences the mass of substrate retained by the membrane and, thus, the biological process in the MBR. The results show that a modeller should not exclude the role of phosphorus in the contribution of accumulating organisms during the prediction of GHGs due to the high interaction of $\mathrm{N}_{2} \mathrm{O}$. The results reveal that the uncertainty in the emission factors for $\mathrm{CO}_{2}$ is higher than the uncertainty in the emission factors for $\mathrm{N}_{2} \mathrm{O}$ (namely, 2.2 and $0.17 \%$, respectively).
\end{abstract}

(c) 2014 Elsevier B.V. All rights reserved.

\section{Introduction}

Over the last decade, the interest in greenhouse gas (GHG) emissions from wastewater treatment plants (WWTPs) significantly increased [1-4]. During wastewater treatment, GHGs such as carbon dioxide $\left(\mathrm{CO}_{2}\right)$, methane $\left(\mathrm{CH}_{4}\right)$ and nitrous oxide $\left(\mathrm{N}_{2} \mathrm{O}\right)$ are emitted to the atmosphere and contribute to global warming [5].

Several attempts to quantify GHG emissions from WWTPs have been performed in previous years and numerous plant configurations and technologies have been investigated (e.g., [6,7]). An extensive range of GHG emissions is reported in the literature, which mainly refers to a predominance of $\mathrm{N}_{2} \mathrm{O}$ emissions, making difficult a comprehensive comparison of the different systems $[8,9]$. The fixed conversion factors employed by the International Panel on Climate Change (IPCC) for estimating the GHG emissions

\footnotetext{
* Corresponding author. Tel.: + 39091 23896556; fax: + 3909123860810.

E-mail address: giorgio.mannina@unipa.it (G. Mannina).
}

from WWTPs are highly uncertain [10,11]. Improvements in the measurement techniques and tools for GHG quantification are imperative. In this context, mathematical modelling assumes a key role. Mathematical models facilitate the quantification of GHG emissions for different wastewater treatment systems and the assessment of the effects of their operating conditions. Mathematical modelling enables an adequate estimation of the necessary emission factors because it considers the variability in the carbon and nitrogen influent and the involved processes in WWTPs. Mathematical models represent valid tools for developing strategies that are aimed at reducing GHG emissions and improving environmental protection. As suggested by Corominas et al. [3], different types of mathematical models (i.e., empirical, mechanistic and simple comprehensive process models) are available for estimating GHG emissions (e.g., [2,12-15]). Previous mathematical models were empirical and based on emission factors that have been evaluated by using measured data [16,17]. However, due to the oversimplification of empirical emission factors, the reliability of model predictions is uncertain [3]. Indeed, as underlined by 
Kampschreur et al. [1] for the $\mathrm{N}_{2} \mathrm{O}$ emission, literature data shows a huge variation both in pilot and full scale studies.

Therefore, recent efforts in the development of new processes based on mechanistic dynamic models have been initiated [11,15]. These models, which primarily focus on modelling $\mathrm{N}_{2} \mathrm{O}$ emissions, assess $\mathrm{CO}_{2}$ emissions that are related to biological processes using emission factors. These models possess the advantage of estimating GHG emissions by considering effective plant design and operating conditions as well as the variability of the influent wastewater $[2,18-20]$. Using a virtual case study characterised by synthetic data (i.e., not a real WWTP), Corominas et al. [3] demonstrated that the assessment of GHGs by empirical models (based on a single emission factor) can produce erroneous results as the formation of GHGs is not a linear process. These results primarily stem from the idea that a single emission factor is not able to reproduce the variability of the GHG production related to changes in plant configuration, operating conditions and variability of the influent. Compared with empirical models, mechanistic process-based dynamic models are required to obtain an accurate estimation of GHG emissions [3]. Based on the findings of Corominas and co-workers, some researchers have begun to develop and employ mechanistic process-based dynamic models (e.g., $[10,11])$.

Despite the useful insights derived by mathematical models of GHG emissions from WWTPs, the results are likely to be subjected to a high degree of uncertainty [11]. An assessment of the uncertainty in GHG emissions can be useful and may aid in the efficient calibration of mathematical models. Sensitivity and uncertainty analyses can be useful tools for identifying the key sources that control model outputs [21]. Despite the potential for uncertainty and sensitivity analyses, few studies on the estimation of GHG emissions from WWTPs have been performed. Recently, Sweetapple et al. [11] applied the local and global sensitivity analysis (GSA) methods, which identified the model factors that significantly influence the model outputs of a mechanistic model of the ASM family. "Factors" is a term widely used in the sensitivity analysis literature and includes model parameters and model input variables [28]. In addition to useful insights, the employed GHG mathematical model was applied to a virtual (i.e., not a real case study) WWTP; the results were not validated with real data. The source of uncertainty in modelling GHG emissions was only derived for a conventional activated sludge (CAS) system. This derivation also identified a gap in the literature on the application of GHG modelling. Studies on GHG mathematical models of advanced wastewater treatment systems, such as MBRs, have not been performed. The MBR systems are characterised by specific peculiarities that hamper a possible transferability of the results derived for CAS systems [22-24]. In contrast with CAS systems, MBR systems are characterised by solid-liquid separation, high concentrations of suspended solids and high sludge retention times, which induce large differences in the sludge properties and dynamic behaviour of MBR systems [25,26]. These differences, which have been experimentally investigated by several authors, fundamentally highlight the stability of the autotrophic biomass activity in MBR systems compared with CAS systems (among others, [27]).

To address this gap in the literature, this paper presents a mathematical model that is capable of quantifying the GHG emissions from a MBR system; the model was applied to a University Cape Town (UCT) MBR pilot plant. Sensitivity and uncertainty analyses that consider three performance indicators - GHG emissions $\left(\mathrm{CO}_{2}\right.$ and $\mathrm{N}_{2} \mathrm{O}$ ), effluent quality and economic costs - were also performed. Model factors were classified by applying two global sensitivity analysis methods (namely, the standardised regression coefficient (SRC) method and the Extended-FAST method) to reduce the computational cost associated with the GSA [28].

The principal objectives of this study are as follows: (i) to establish a new mathematical tool for quantifying GHG emissions from the MBR system; (ii) to identify the primary factors that influence the performance indicators (namely, GHG emissions, effluent quality and economic costs); (iii) to quantify the variance contribution of the model factors; and (iv) to evaluate the uncertainty in the model predictions.

\section{Materials and methods}

\subsection{Model description}

The proposed mathematical model couples the integrated ASM2d-SMP model introduced by Cosenza et al. [24] with the GHG model of Hiatt and Grady [13].

The proposed mathematical model (ASM2d-SMP-GHG) is divided into two sub-models: a biological sub-model and a physical sub-model. The physical sub-model simulates the main processes related to the membrane: the rates of sludge attachment and sludge detachment on the membrane surface throughout the suction and backwashing phases, the solid mass deposited on the membrane surface, the thickness of the cake layer and pore fouling by the resistance in the series model [29] and the involvement of 6 model factors. The physical sub-model simulates the permeate COD profile inside the cake layer according to the deep bed theory [30]. Particles are retained inside the cake layer and contribute to the reduction of the total COD concentration in the effluent, which serves as a biological filter/barrier [30]. Additional details on the physical sub-model are included in the literature [24,30].

The biological sub-model simulates the main biological processes that occur in the bioreactors according to the philosophy of the ASM [31]. The biological sub-model involves 39 biological processes $(j), 24$ state variables $(i), 39$ stoichiometric parameters (including 11 conversion factors for COD and charge) and 64 kinetic parameters (including two oxygen transfer coefficients), and 6 fractionation coefficients of influent COD. The stoichiometric, kinetic and influent fractionation model parameters are identified here by the term "model factors". Table 1 summarise the model state variables. For sake of conciseness supplementary materials containing details about the mathematical model are provided (Tables 1A-3A). Specifically Tables 1A-3A summarise the model factors, the kinetic Gujer matrix and the stoichiometric Gujer matrix, respectively.

The ASM2d-SMP-GHG model also simulates the soluble carbon dioxide $\left(S_{\mathrm{CO}_{2}}\right)$. The stoichiometric coefficients for $S_{\mathrm{CO}_{2}}$ modelling have been evaluated using the continuity-based model interface proposed by Vanrolleghem et al. [32]. The continuity of the final Gujer's model matrix has been verified, as proposed by Hauduc et al. [33]. The model also addresses the influence of seasonal variability by considering the dependency on temperature for the following terms: liquid-gas saturation constants, kinetic parameters, transfer coefficients and equilibrium reactions. The model also includes the stripping processes for $\mathrm{N}_{2} \mathrm{O}$ and $\mathrm{CO}_{2}$.

Regarding the nitrogen removal processes, the ASM2d-SMPGHG model includes a two-step nitrification process and a fourstep denitrification process according to Hiatt and Grady [13]. Errors in the Hiatt and Grady [13] model, which were previously identified by Corominas et al. [3], were corrected. The two-step nitrification process includes two microbial autotrophic populations - ammonia-oxidising bacteria $(\mathrm{AOB})$ and nitrite-oxidising bacteria (NOB) - instead of a unique autotrophic population such as the ASM2d. Therefore, two new particulate state variables are considered instead of autotrophic biomass $\left(X_{\mathrm{AUT}}\right)$ : the ammoniaoxidising biomass $\left(X_{\mathrm{AOB}}\right)$ and the nitrite-oxidising biomass $\left(X_{\mathrm{NOB}}\right)$ (Table 1). Fig. 1 shows a simplified scheme of the processes associated with the two-step nitrification process and the fourstep denitrification process. Important to precise is that the 
ASM2d-SMP-GHG model does not include the nitrifier denitrification process. Indeed, due to the high complexity of the modelled system it has been decided to use the more consolidated and also much more employed in other studies [among others, 2,3,11,34] model proposed by Hiatt and Grady [13] that considers only the heterotrophic denitrification pathway. Furthermore, as discussed by $\mathrm{Ni}$ et al. [19] the existing models that include the AOB denitrification pathway are not able to reproduce the measured data of $\mathrm{N}_{2} \mathrm{O}$ and thus a clear interpretation and mathematical modelling approach has not yet established. According to the ASM2d-SMP-GHG model, the $X_{\mathrm{AOB}}$ and $X_{\mathrm{NOB}}$ biomass use free ammonia $\left(S_{\mathrm{FA}}\right)$ and free nitrous acid $\left(S_{\mathrm{FNA}}\right)$, respectively, as substrates (refer to the rates for processes 36 and 27 in Table 2A). Consequently, the half-saturation coefficients for $S_{\mathrm{FA}}$ (namely, $K_{\mathrm{FA}}$ )

Table 1

Model state variables.

\begin{tabular}{lll}
\hline Symbol & Definition & Unit \\
\hline$S_{\mathrm{O} 2}$ & Dissolved oxygen & $\mathrm{kg} \mathrm{COD} \mathrm{m}^{-3}$ \\
$S_{\mathrm{F}}$ & Fermentable organic matter & $\mathrm{kg} \mathrm{COD} \mathrm{m}^{-3}$ \\
$S_{\mathrm{A}}$ & Fermentation product (acetate) & $\mathrm{kg} \mathrm{COD} \mathrm{m}^{-3}$ \\
$S_{\mathrm{BAP}}$ & Soluble biomass associated products & $\mathrm{kg} \mathrm{COD} \mathrm{m}^{-3}$ \\
$S_{\mathrm{UAP}}$ & Soluble utilisation associated products & $\mathrm{kg} \mathrm{COD} \mathrm{m}^{-3}$ \\
$\mathrm{~S}_{\mathrm{NH}_{4}}$ & Ammonia & $\mathrm{kg} \mathrm{N} \mathrm{m}^{-3}$ \\
$S_{\mathrm{NO}_{3}}$ & Nitrate & $\mathrm{kg} \mathrm{N} \mathrm{m}^{-3}$ \\
$S_{\mathrm{NO}_{2}}$ & Nitrite & $\mathrm{kg} \mathrm{N} \mathrm{m}^{-3}$ \\
$S_{\mathrm{NO}}$ & Nitric oxide & $\mathrm{kg} \mathrm{N} \mathrm{m}^{-3}$ \\
$S_{\mathrm{N}_{2} \mathrm{O}}$ & Nitrous oxide & $\mathrm{kg} \mathrm{N} \mathrm{m}^{-3}$ \\
$S_{\mathrm{N}_{2}}$ & Dissolved nitrogen gas & $\mathrm{kg} \mathrm{N} \mathrm{m}^{-3}$ \\
$S_{\mathrm{PO} 4}$ & Soluble inorganic phosphorus & $\mathrm{kg} \mathrm{P} \mathrm{m}^{-3}$ \\
$S_{\mathrm{I}}$ & Soluble undegradable organics & $\mathrm{kg} \mathrm{COD} \mathrm{m}^{-3}$ \\
$S_{\mathrm{ALK}}$ & Alkalinity (HCO & (H) \\
$S_{\mathrm{CO}}$ & Dissolved carbon dioxide & $\mathrm{mol} \mathrm{HCO}_{3}^{-} \mathrm{m}^{-3}$ \\
$X_{\mathrm{I}}$ & Particulate undegradable organics from the influent & $\mathrm{kg} \mathrm{COD} \mathrm{m}^{-3}$ \\
$X_{\mathrm{S}}$ & Particulate biodegradable organics & $\mathrm{kg} \mathrm{COD} \mathrm{m}^{-3}$ \\
$X_{\mathrm{H}}$ & Heterotrophic organisms & $\mathrm{kg} \mathrm{COD} \mathrm{m}^{-3}$ \\
$X_{\mathrm{PAO}}$ & Phosphorus Accumulating Organisms (PAOs) & $\mathrm{kg} \mathrm{COD} \mathrm{m}^{-3}$ \\
$X_{\mathrm{PP}}$ & Stored polyphosphates in PAOs & $\mathrm{kg} \mathrm{P} \mathrm{m}^{-3}$ \\
$X_{\mathrm{PHA}}$ & Storage compound in PAOs & $\mathrm{kg} \mathrm{COD} \mathrm{m}^{-3}$ \\
$X_{\mathrm{AOB}}$ & Ammonia Oxidising Bacteria (AOB) & $\mathrm{kg} \mathrm{COD} \mathrm{m}^{-3}$ \\
$X_{\mathrm{NOB}}$ & Nitrite Oxidizing Bacteria & $\mathrm{kg} \mathrm{COD} \mathrm{m}^{-3}$ \\
$X_{\mathrm{TSS}}$ & Total suspended solids & $\mathrm{kg} \mathrm{COD} \mathrm{m}^{-3}$ \\
\hline & &
\end{tabular}

and $S_{\mathrm{FNA}}$ (namely, $K_{\mathrm{FNA}}$ ) are introduced and considered in the aerobic growth of $X_{\mathrm{AOB}}$ and $X_{\mathrm{NOB}}$. The growth of $X_{\mathrm{AOB}}$ and $X_{\mathrm{NOB}}$ is simulated (Fig. 1) as a two-step nitrification process with the formation of nitrite $\left(S_{\mathrm{NO}_{2}}\right)$ and nitrate $\left(\mathrm{S}_{\mathrm{NO}_{3}}\right)$ [13]. The rate of the aerobic growth of $X_{\mathrm{AOB}}$ (process 36 , Table $2 \mathrm{~A}$ ) considers the role of the dissolved oxygen inside the aerobic tank (using the halfsaturation coefficient $K_{\mathrm{O}, \mathrm{AOB}}$ ) and the inhibition effect of the $S_{\mathrm{FA}}$ concentration (as a function of $K_{\mathrm{FA}}$ ) and the $S_{\mathrm{FNA}}$ concentration (as a function of $K_{\mathrm{FNA}}$ ).

Similar to Hiatt and Grady's model, the concentrations of $S_{\mathrm{FA}}$ and $S_{\mathrm{FNA}}$ are modelled as a function of the total ammonia concentration $\left(S_{\mathrm{NH}_{4}}\right)$ and the soluble nitrite concentration $\left(S_{\mathrm{NO}_{2}}\right)$, respectively. The rate of $X_{\mathrm{NOB}}$ growth considers the inhibition effects of the oxygen in $S_{\mathrm{FA}}$ and $S_{\mathrm{FNA}}$ (process 37, Table 2A).

The four-step denitrification process involves the heterotrophic biomass $\left(X_{\mathrm{H}}\right)$ and the biomass of the phosphorus-accumulating organisms $\left(X_{\mathrm{PAO}}\right)$ and considers $S_{\mathrm{NO}_{2}}$, nitric oxide $\left(S_{\mathrm{NO}}\right)$ and nitrous oxide $\left(S_{\mathrm{N}_{2} \mathrm{O}}\right)$ to be the intermediate products (see Table 1 and Fig. 1). The latter products have been added to the soluble nitrate $\left(S_{\mathrm{NO}_{3}}\right)$ and dissolved nitrogen gas $\left(S_{\mathrm{N}_{2}}\right)$ variables to describe the entire nitrogen removal process. The presence of $S_{\mathrm{N}_{2}}$ as a state variable closes the mass balance equation for the nitrogen. The stoichiometric conversion factors of the COD for $S_{\mathrm{NO}_{3}}\left(i_{C O D} \mathrm{NO}_{3}\right)$, $S_{\mathrm{NO}_{2}}\left(i_{\mathrm{COD}_{-} \mathrm{NO}_{2}}\right), S_{\mathrm{NO}}\left(i_{\mathrm{COD}_{-} \mathrm{NO}}\right), S_{\mathrm{N}_{2} \mathrm{O}}\left(i_{\mathrm{COD}_{-} \mathrm{N}_{2} \mathrm{O}}\right)$ and $S_{\mathrm{N}_{2}}\left(i_{\mathrm{COD}_{-} \mathrm{N}_{2} 2}\right)$ are considered for the model matrix according to the procedure suggested in the literature [34]. To include the four steps of denitrification, the processes of anoxic heterotrophic biomass growth on fermentable organic matter $\left(S_{\mathrm{F}}\right)$ and acetate $\left(S_{\mathrm{A}}\right)$ and both the anoxic storage of polyphosphate $\left(X_{\mathrm{PP}}\right)$ and the anoxic growth of $X_{\mathrm{PAO}}$, have been modified (processes 12-15, 16-19, 24-27 and 29-32 in Tables 2A-3A, respectively). Each of these processes has been partitioned into four steps: 1) $S_{\mathrm{NO}_{3}}$ reduction to $S_{\mathrm{NO}_{2}}$, 2) $S_{\mathrm{NO}_{2}}$ reduction to $\left.S_{\mathrm{NO}}, 3\right) S_{\mathrm{NO}}$ reduction to $S_{\mathrm{N}_{2} \mathrm{O}}$ and 4) $S_{\mathrm{N}_{2} \mathrm{O}}$ reduction to $S_{\mathrm{N}_{2}}$ (Fig. 1, Tables $2 \mathrm{~A}$ and $3 \mathrm{~A}$ ). The correction factors for the heterotrophic anoxic growth rate, which reduce $S_{\mathrm{NO}_{3}}$ to $S_{\mathrm{NO}_{2}}\left(\eta_{g 2}\right), S_{\mathrm{NO}_{2}}$ to $S_{\mathrm{NO}}\left(\eta_{g 3}\right), S_{\mathrm{NO}}$ to $S_{\mathrm{N}_{2} \mathrm{O}}\left(\eta_{g 4}\right)$ and $S_{\mathrm{N}_{2} \mathrm{O}}$ to $S_{\mathrm{N}_{2}}\left(\eta_{g 5}\right)$, are introduced by Hiatt and Grady [13] (Table 1A). These correction factors have been added to the process rate equations 12-19 (Table 2A). Note that though the model considers the biological phosphorus removal processes according to the ASM2d [31], it also

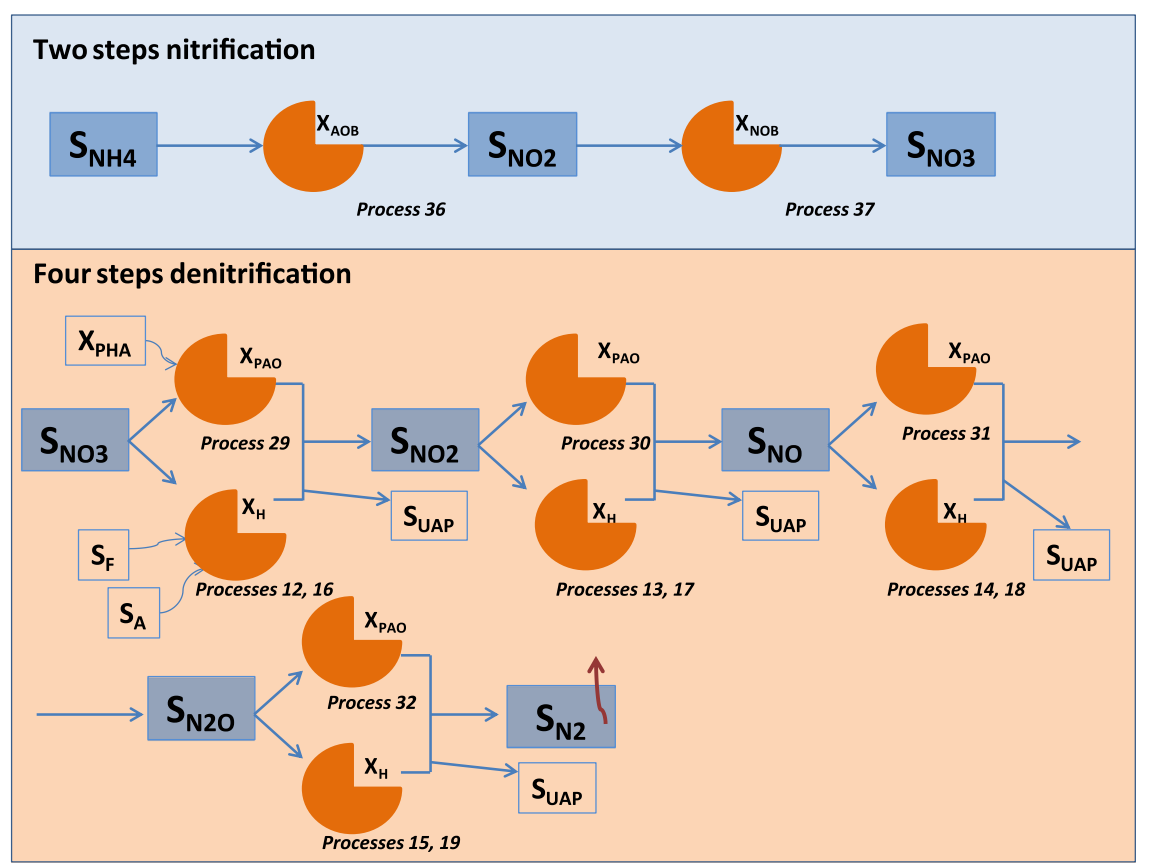

Fig. 1. Simplified scheme of the two steps nitrification and four steps denitrification processes (the process number is according to Table $2 \mathrm{~A}$ ). 
considers the contribution of $X_{\mathrm{PAO}}$ in the GHG formation. Therefore, the correction factors for the $X_{\mathrm{PAO}}$ anoxic growth rate (i.e., $\eta_{\mathrm{PAO}_{2}}, \eta_{\mathrm{PAO}_{3}}, \eta_{\mathrm{PAO}_{4}}$ and $\eta_{\mathrm{PAO}_{5}}$ ) are based on $\eta_{\mathrm{NO}_{3}, \mathrm{PAO}}$ and $\eta_{\mathrm{NO}_{3}, \mathrm{H}}$. The ratio between the $\eta_{g 2}$ (or $\eta_{g 3}, \eta_{g 4}, \eta_{g 5}$ ) and $\eta_{\mathrm{NO}_{3}, \mathrm{H}}$ factors is equivalent to the ratio between the $\eta_{\mathrm{PAO}_{2}}$ (or $\eta_{\mathrm{PAO}_{3},}, \eta_{\mathrm{PAO}_{4}}$ and

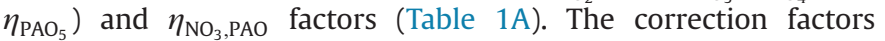
introduced for $X_{\mathrm{PAO}}$ have been added to the rate equations of processes 24-27 and 29-32 (Table 2A).

In the biological sub-model, the soluble microbial products (SMPs) in the formation/degradation processes are modelled by considering the substrate utilisation and the biomass-associated products $\left(S_{\mathrm{UAP}}\right.$ and $S_{\mathrm{BAP}}$ ). Specifically, $S_{\mathrm{BAP}}$ production is proportional to the biomass decay, which is based on the proportional coefficient $f_{\mathrm{BAP}}$ (fraction of $S_{\mathrm{BAP}}$ generated per biomass decayed). The $S_{\mathrm{BAP}}$ reduction, which occurs during the hydrolysis processes (processes 1-3, 21, 33, 38 and 39), comprises first-order kinetics that are based on the hydrolysis rate coefficient $k_{\text {H,BAP. }}$ The production and degradation of $S_{U A P}$ are similarly described by considering the coefficients $f_{\mathrm{UAP}}$ (fraction of $S_{\mathrm{UAP}}$ generated during biomass decay) and $k_{\text {H,UAP. }} S_{\text {UAP }}$ is reduced during the hydrolysis processes 4-6 (Table $3 \mathrm{~A}$ ). The production of $S_{\mathrm{UAP}}$ Occurs during the aerobic growth of $X_{\mathrm{H}}$ (processes 10 and 11, Tables $2 \mathrm{~A}$ and $3 \mathrm{~A}$ ) and the nitrification processes (processes 36 and 37, Tables 2A and 3A). During all modelled nitrogen reduction processes (refer to processes $12-15-19$, and $28-32$ of Tables $2 A-3 A$ ), $S_{\text {UAP }}$ is produced (see Fig. 1). Regarding the stripping of GHGs, the $\mathrm{CO}_{2}$ and $\mathrm{N}_{2} \mathrm{O}$ emissions have been quantified using the following equations:

$\mathrm{CO}_{2}=K_{L} a_{\mathrm{O}_{2}} \cdot \frac{\sqrt{D_{\mathrm{O}_{2}}}}{\sqrt{D_{\mathrm{CO}_{2}}}}\left(S_{\mathrm{CO}_{2}, s}-S_{\mathrm{CO}_{2}, l}\right)$

$\mathrm{N}_{2} \mathrm{O}=K_{L} a_{\mathrm{O}_{2}} \cdot \frac{\sqrt{D_{\mathrm{O}_{2}}}}{\sqrt{D_{\mathrm{N}_{2} \mathrm{O}}}}\left(S_{\mathrm{N}_{2} \mathrm{O}, s}-S_{\mathrm{N}_{2} O, l}\right)$

where $K_{L} a_{\mathrm{O} 2}$ is the oxygen transfer coefficient; $D_{\mathrm{O}_{2}}, D_{\mathrm{CO}_{2}}$ and $D_{\mathrm{N}_{2} \mathrm{O}}$ are the diffusion coefficients in water at $293.15 \mathrm{~K}$ for oxygen, carbon dioxide and nitrous oxide, respectively; $S_{\mathrm{CO}_{2}, \mathrm{~s}}$ and $\mathrm{S}_{\mathrm{N}_{2} \mathrm{O}, \mathrm{s}}$ are the saturation concentrations in the liquid phase of $\mathrm{CO}_{2}$ and $\mathrm{N}_{2} \mathrm{O}$, respectively; and $S_{\mathrm{CO}_{2,1}}$ and $\mathrm{S}_{\mathrm{N}_{2} \mathrm{O}, 1}$ are the concentrations of $\mathrm{CO}_{2}$ and $\mathrm{N}_{2} \mathrm{O}$, respectively, in the liquid phase.

To address the nature of different GHG emissions $\left(\mathrm{CO}_{2}\right.$ and $\mathrm{N}_{2} \mathrm{O}$ ), $\mathrm{N}_{2} \mathrm{O}$ emissions are converted into the equivalent units of $\mathrm{CO}_{2}$ $\left(\mathrm{CO}_{2 \mathrm{eq}}\right)$ using the GWP value of $298 \mathrm{~kg} \mathrm{CO} \mathrm{CO}_{2 \text { eq }}$ per $\mathrm{kg} \mathrm{N} \mathrm{N}_{2} \mathrm{O}$ proposed by IPCC [17].

\subsection{Case study}

The model has been applied to a UCT-MBR pilot plant that was fed with $40 \mathrm{~L} \mathrm{~h}^{-1}$ of municipal wastewater for 165 days. The pilot plant (Fig. 2) consists of three reactors in series - anaerobic, anoxic and aerobic - and an aerobic tank, in which two hollow fibre membrane modules (Zenon Zeeweed, ZW 10) are submerged. To maintain the required biomass concentration for biological activity, recycled fluxes from membrane tank to aerobic tank, from aerobic to anoxic tank and from anoxic to anaerobic tank are considered. Until day 76, the plant was operated with complete sludge retention; after day 76, the sludge was regularly withdrawn to maintain a sludge age of 37 days. During the entire experimental period, the following samples were obtained (Fig. 2): composite influent wastewater samples (section 0), mixed liquor grab samples in each tank (i.e., anaerobic, anoxic, aerobic and MBR tanks, Sections 1-4), and mixed liquor samples in the oxygen depletion reactor (section 6) and the permeate (section 5). This process was performed three times per week, and the samples were analysed for total suspended solids (TSS), volatile suspended solids (VSS), total and soluble $\mathrm{COD}, \mathrm{NH}_{4}-\mathrm{N}, \mathrm{NO}_{2}-\mathrm{N}, \mathrm{NO}_{3}-\mathrm{N}, \mathrm{N}_{\text {TOT }}$ and $\mathrm{P}_{\text {Тот }}$ [35]. Additional details about pilot plant and sampling campaign are included in the literature [24,36].

\subsection{Performance indicators}

Three performance indicators have been used as reference model outputs for classifying the model factors: the effluent quality index (EQI), the operational costs (OCs) and the GHG emissions $\left(\mathrm{CO}_{2}\right.$ and $\left.\mathrm{N}_{2} \mathrm{O}\right)$.

\subsubsection{Effluent quality index-EQI}

The EQI [ $\mathrm{kg} \mathrm{PU} \mathrm{d}^{-1}$ ] represents the pollutant mass that are discharged throughout the evaluation period; it is calculated as follows [37]:

$\mathrm{EQI}=\frac{1}{T \cdot 1000} \int_{t_{0}}^{t_{1}}\left(\beta_{\mathrm{COD}} \cdot \mathrm{COD}_{\mathrm{e}}+\beta_{\mathrm{NH}} \cdot S_{\mathrm{NHe}}+\beta_{\mathrm{NO}} \cdot S_{\mathrm{NOe}}+\beta_{\mathrm{PO}} \cdot S_{\mathrm{POe}}\right) \cdot Q_{\text {eff }} d t$

where $\beta_{\mathrm{COD}}, \beta_{\mathrm{NH}}, \beta_{\mathrm{NO}}$ and $\beta_{\mathrm{PO}}$ are the weighting factors of the effluent concentrations of $\operatorname{COD}\left(\mathrm{COD}_{\mathrm{e}}\right)$, ammonia $\left(S_{\mathrm{NHe}}\right)$, nitrate $\left(S_{\mathrm{NO}}\right)$ and orthophosphate $\left(S_{\mathrm{POe}}\right)$, respectively. In this study, the following weighting factors were employed [38]: $\beta_{\mathrm{COD}}=1$, $\beta_{\mathrm{NH}}=20, \beta_{\mathrm{NO}}=20$ and $\beta_{\mathrm{PO}}=50$.

\subsubsection{Operational costs-OC}

The OC $\left[€ \mathrm{~m}^{-3}\right]$ are related to the total costs of the MBR plant operation. In particular, the OC have been calculated by adapting the cost function proposed by Vanrolleghem and Gillot [39] for MBR systems as follows [38]:

$\mathrm{OC}=\left(P_{\mathrm{w}}+P_{\text {eff }}\right) \cdot \gamma_{\mathrm{e}}+\mathrm{CC}+\mathrm{EF}$

where $P_{\mathrm{w}}$ and $P_{\text {eff }}$ are the energy requirements per $\mathrm{m}^{3}$ of permeate extracted for aeration extraction and permeate extraction, respectively, $\left[\mathrm{kW} \mathrm{h} \mathrm{m}^{-3}\right] ; \gamma_{e}\left[€ \mathrm{~kW} \mathrm{~h}^{-1}\right]$ is the cost of $1 \mathrm{~kW} \mathrm{~h}$; EF [€ $\left.\mathrm{m}^{-3}\right]$ is the cost of the effluent fines; and CC $\left[€ \mathrm{~m}^{-3}\right]$ is the cost of the chemicals used for membrane cleanings. In particular, CC is calculated by considering a typical membrane cleaning protocol that includes a solution composed of $500 \mathrm{ppm}$ of $\mathrm{NaOCl}$ and $2000 \mathrm{ppm}$ of citric acid, with a value of $0.48 €$ per chemical cleaning. According to Italian fare, the cost of electricity of $0.0806 € \mathrm{~kW} \mathrm{~h}^{-1}$ is used to evaluate $\gamma_{e}$. A frequency of one chemical cleaning per month has been considered.

\subsubsection{Power requirement}

To evaluate $P_{\mathrm{w}}$, the power requirement $\left(P_{\mathrm{w}, \mathrm{p}}\right)$ for each blower of adiabatic compression is evaluated as follows [40]:

$P_{w, p}=\frac{w R T}{29.7(0.283) e}\left[\left(\frac{p_{2}}{p_{1}}\right)^{0.283}-1\right]$

where $P_{\mathrm{w}, \mathrm{p}}[\mathrm{kW}]$ is the power requirement for each blower; $w$ is the mass flow of air $[\mathrm{kg} / \mathrm{s}] ; R$ is the gas constant for air $[8.314 \mathrm{~kJ} / \mathrm{kmol} / \mathrm{K}]$; $T$ is the absolute temperature [K]; $p_{1}$ and $p_{2}$ are the absolute inlet pressure and absolute outlet pressure [atm], respectively; 29.7 is a constant according to the International System of Units; 0.283 is a constant for air; and $e$ is the blower efficiency (common range: 0.7-0.9).

To calculate $P_{\text {eff, }}$, the power requirement for pumping permeate flow $\left(Q_{\text {eff }}\right)$ has been evaluated as follows [41]:

$P_{\text {eff }, p}=\frac{1}{t_{1}-t_{0}} \int_{t_{0}}^{t_{1}} \frac{\mathrm{TMP} Q_{\mathrm{eff}}(t)}{3600 \eta} d t$

where $P_{\text {eff,p }}[\mathrm{kW}]$ is the permeate pumping power requirement; TMP $[\mathrm{kPa}]$ is the trans-membrane pressure; $Q_{\text {eff }}\left[\mathrm{m}^{3} / \mathrm{h}\right]$ is the effluent flow rate; $t_{0}$ and $t$ are the initial time and final time, 


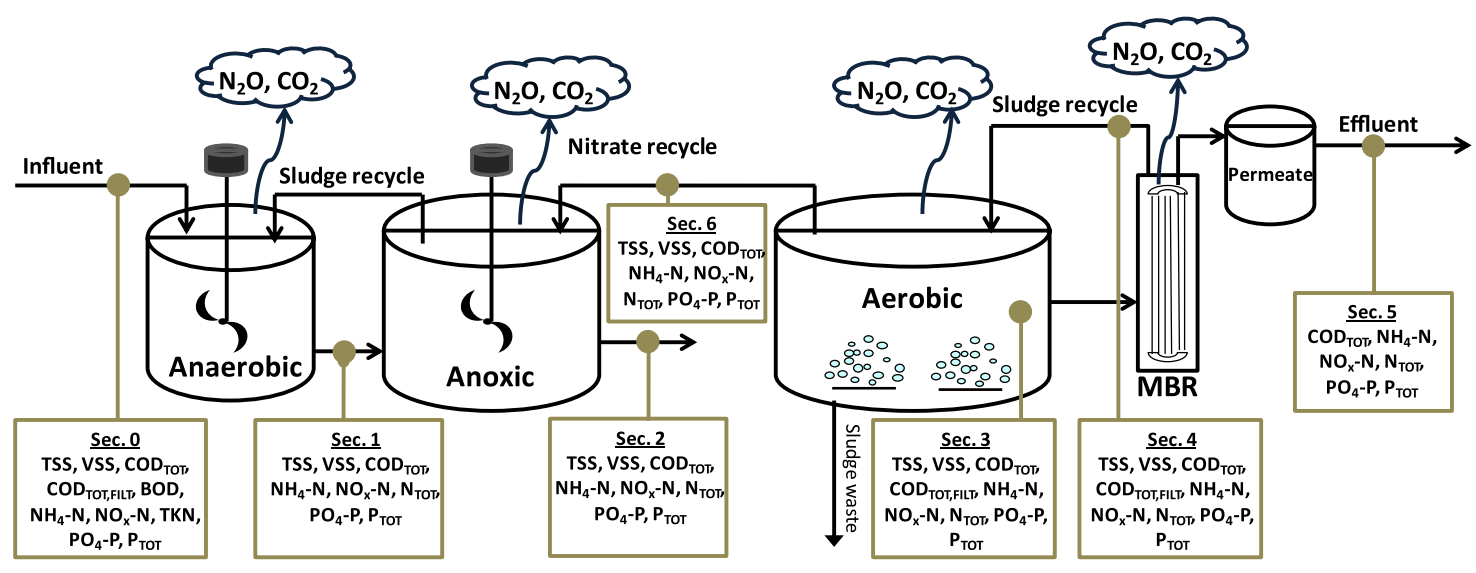

Fig. 2. Scheme of the MBR pilot plant.

respectively, of pump operation; and $\eta$ is the permeate pump efficiency.

\subsubsection{Effluent fines-EF}

The cost related to the $\mathrm{EF}$ is computed by comparing the effluent concentration $\left(C_{j}^{\mathrm{EFF}}\right)$ with the effluent limits $\left(C_{L, j}\right)$ for each relevant pollutant $(j)$ during the evaluation period $\left(t_{2}-t_{1}\right)$ expressed as follows [38,42]:

$$
\begin{aligned}
\mathrm{EF}= & \frac{1}{t_{2}-t_{1}} \cdot \int_{t_{1}}^{t_{2}}\left[\frac { 1 } { Q _ { I N } } \cdot \left(\sum _ { j = 1 } ^ { n } \left(Q_{\mathrm{eff}} \cdot \Delta \alpha_{j} \cdot C_{j}^{\mathrm{EFF}}+\left(Q_{\mathrm{eff}}\right) \cdot\left[\beta_{0, j}\right.\right.\right.\right. \\
& \left.\left.\left.\left.+\left(C_{j}^{\mathrm{EFF}}-C_{L, j}\right) \cdot\left(\Delta \beta_{j}-\Delta \alpha_{j}\right)\right]\right) \cdot\left(\text { Heaviside } \cdot\left(C_{j}^{\mathrm{EFF}}-C_{L, j}\right)\right)\right)\right] \cdot d t
\end{aligned}
$$

where $Q_{\text {IN }}$ and $Q_{\text {eff }}$ are the influent flow and effluent flow, respectively; $\Delta \alpha_{j}$ represents the slope of the curve $E F$ versus $C_{j}^{\mathrm{EFF}}$ when $C_{j}^{\mathrm{EFF}}\left\langle C_{L, j}\right.$ (in this case, the function Heaviside $=0$ ); $\Delta \beta_{j}$ represents the slope of the curve EF versus $C_{j}^{\mathrm{EFF}}$ when $C_{j}^{\mathrm{EFF}}>C_{L, j}$ (in this case, Heaviside $=1$ ); and $\beta_{0, j}$ are the increment of fines for the latter case.

In this study, the concentrations of total COD ( $\left.\mathrm{COD}_{\mathrm{TOT}}\right)$, ammonium $\left(S_{\mathrm{NH}}\right)$, nitrate $\left(S_{\mathrm{NO}_{3}}\right)$ and phosphate $\left(S_{\mathrm{PO}}\right)$ in the permeate are considered to be relevant pollutants. The same $C_{j}^{\mathrm{EFF}}$ value reported by Stare et al. [43] is considered for each pollutant. For each considered relevant pollutant, the value of $C_{L, j}$ is based on the emissions limits mandated by Italian laws [38].

\subsection{Classification methodology of the model factors}

As suggested in the literature, to reduce the GSA computational costs, which can be critical for complex environmental models, a complementary multiple use of GSA methods is advisable $[28,44,45]$. A two-step procedure is adopted for classifying the model factors. The employed methodology is based on the application of two sensitivity analysis methods (namely, SRC and Extended-FAST). The SRC method, which considers the analysis of the total model factors, is applied in the first step. The results of the SRC method are used to apply the Extended-FAST method in the second step. In particular, a subset of the model factors that are selected by the SRC is considered for an extensive analysis aimed at quantifying the interactions among the factors.

\subsubsection{The standardised regression coefficients-SRC}

The SRC method consists of a Monte Carlo simulation (with random sampling of the model factors) and a multivariate linear regression between the model output and the considered model factors. The absolute value of the standardised regression slopes of the regression (SRC or $\beta_{\mathrm{i}}$ ) represents a valid measure of sensitivity when the coefficient of determination $\left(R^{2}\right)$ is greater than 0.7 , as suggested by Saltelli et al. [28]. In the case of a linear model, $R^{2}$ is equal to 1 , and the SRC method can be applied to select important and non-influential model factors. Conversely, when the $R^{2}$ is less than 1, the model factors interact, and the SRC method does not provide any information about the interacting factors. Thus, the SRC method can be applied to nonlinear models only in terms of the selection of important model factors. To apply the SRC method, 500 and 1000 simulations are required as suggested in the literature [46].

\subsubsection{The Extended-FAST}

The Extended-FAST method provides two sensitivity indices for each $i$ th model factor: the first-order effect index $\left(S_{\mathrm{i}}\right)$ and the totaleffect index $\left(S_{\mathrm{Ti}}\right)$. $S_{\mathrm{i}}$ quantifies the contribution of the $i$ th model factor to the variance of the model output $(\operatorname{Var}(Y))$ without considering the interaction among the model factors; it is expressed as follows:

$S_{i}=\frac{\operatorname{Var}_{x i}\left(E_{x_{-i}}\left(Y \mid x_{i}\right)\right)}{\operatorname{Var}(Y)}$

where $E$ is the expectancy operator and Var is the variance operator. The subscripts indicate that the operation is either applied "over the $i$ th factor" $X_{i}$, or "over all model factors except the $i$ th model factor" $X_{i}$ [28].

$S_{\mathrm{Ti}}$ provides information about the interaction among the model factors and is expressed as follows:

$S_{T i}=1-\frac{\operatorname{Var}_{X_{-i}}\left(E_{X_{i}}\left(Y \mid X_{-i}\right)\right)}{\operatorname{Var}(Y)}$

The difference between $S_{\mathrm{Ti}}$ and $S_{\mathrm{i}}$ represents the interaction among the model factors (IF). In terms of using the Extended-FAST method to classify the model factors, important (high value of $S_{\mathrm{i}}$ ), non-influential (low values of $S_{\mathrm{i}}$ and $S_{\mathrm{Ti}}$ ) and interacting (high value of IF) model factors may be selected.

The Extended-FAST method requires $n$ NMC simulations, where $n$ is the number of factors and NMC is the number of MC simulations per model factor $(\mathrm{NMC}=500-1000$ according to Saltelli et al. [47]).

\subsection{Uncertainty analysis}

The uncertainty analysis has been performed using Monte Carlo simulations that are similar to simulations from previous studies on ASMs (e.g., [48]). The uncertainty analysis is characterised by the following steps: (i) identifying the uncertain model factors; (ii) sampling of the uncertain model factors; (iii) uncertainty 
propagation of the model factors by model running; and (iv) interpreting the results. Step (i) is related to the sensitivity analysis, in which only the model factors selected in the step (ii) of the sensitivity analysis are considered for the uncertainty analysis. In this study, the Latin Hypercube Sampling (LHS) method is employed in step (ii) [49]. The model factors sampled during step (ii) are employed to propagate the uncertainty in the performance indicators that are used as outputs and to evaluate the uncertainty in the model predictions (step iii). An interpretation of the results is performed (step iv).

\subsection{Simulation conditions and numerical settings for the application of GSA and uncertainty analyses}

The values of the GHG-ASM2d-SMP model factors are obtained from model calibration and/or technical literature $[13,24,50]$. In particular, model factors related to the liquid phase have been derived by employing an advanced calibration protocol and conditioning the mathematical model to the quality data collected during an extensive field data campaign at the UCT-MBR pilot plant $[24,36]$. The values of the model factors related to the gas phase have been obtained from the technical literature and the mass balance-continuity check of Gujer's matrix. A combination of the procedures suggested by Vanrolleghem et al. [32] and Hauduc et al. [33] was employed.

The application of both the GSA and uncertainty methods was performed through dynamic simulations. Continuous input time series, which were obtained by employing a truncated Fourier series calibrated on discrete measured input data collected during pilot plant monitoring, were employed [51-53].

Due to the lack of knowledge about the distribution of the model factors, a uniform prior distribution was considered for each factor Dotto et al. [22] demonstrated that due to a lack of relevant information on model factors, a uniform prior distribution should be preferred. Similar to previous studies [53], the variation in each model factor has been obtained by considering a variation of $\pm 5 \%$ with respect to the median value in the literature or the reference value (i.e., Table 1A). To classify important, non-influential and interacting factors, the thresholds of the sensitivity measures were selected according to previous studies $[24,36]$. For model factors for which $\beta_{i}$ was higher than 0.1 , a minimum of at least one performance indicator has been considered important for the SRC application. Model factors with $\beta_{i}$ values less than 0.1 were considered non-influential factors. Regarding the Extended-FAST application, for all model factors with $S_{\mathrm{i}}$ values greater than 0.02 , a minimum of one performance indicator was classified as important. Interacting model factors were selected using the normalised index value $\left(S_{\mathrm{Ni}}\right)$, which corresponds to the ratio between the interaction of the $i$ th model factor related to one performance indicator and the maximum value among the interactions for that performance indicator [24]. In this case, because $S_{\mathrm{Ni}}$ was greater than 0.2 for at least one performance indicator, the factor was considered to be interacting. Model factors with $S_{\mathrm{Ni}}$ and $S_{\mathrm{i}}$ values lower than 0.2 and 0.02 , respectively, were considered to be non-influential.

The GSA methods were applied using the sensitivity package developed by Pujol [26] in the $R$ environment ( $R$ Development Core Team, 2007).

Regarding the uncertainty analysis, only the model factors classified as influential and interacting by the Extended-FAST analysis were considered to be uncertain and varied in the uncertainty range according to the LHS sampling method. The results were interpreted by evaluating the cumulative distribution function (CDF) for each performance indicator.

The number of Monte Carlo simulations required to perform the uncertainty analysis was selected according to previous studies [22]. The uncertainty analysis was performed using a different number of simulations, beginning with 200 steps and increasing by 200 steps in each subsequent simulation. At each step, the cumulated likelihood distributions were compared with the cumulative likelihood distributions in the previous step. The number of Monte Carlo simulations for which the difference between the distributions was less than 0.01 was considered appropriate for the analysis in terms of the Kolmogorov-Smirnov maximum distance [22].

\section{Results and discussion}

\subsection{The SRC results}

To apply the SRC, 1200 model runs were conducted for each model factor. The required number of model runs was confirmed by testing the convergence of the results by increasing the number of Monte Carlo simulations in a stepwise approach and verifying that the difference between two subsequent steps was negligible [23].

Table 2 summarises the results related to the most important model factors for each performance indicator (the important model factors are underlined in grey). Table $4 \mathrm{~A}$ lists the results obtained for all model factors. The $R^{2}$ values, which range between 0.88 and 0.96 , confirm an acceptable degree of linearity for the mathematical model [28]. The high degree of linearity is also confirmed by the value of the sum of the squares of the standardised regression coefficients $\left(\sum \beta^{2}{ }_{i}\right)$, which is close to 1 [28]. From the application of the SRC method, 20 important model factors were determined (underlined in grey in Table 2). The important model factors for each performance indicator are shown in Fig. 3. Based on the results, the model factor $C_{\mathrm{E}}$ (model factor of the physical sub-model that represents the efficiency of backwashing) is characterised by the high sensitivities of the total performance indicators, which demonstrates the relevant roles of the physical processes (Fig. 3). $C_{\mathrm{E}}$ controls the thickness of the mass of particles that accumulates on the membrane (i.e., membrane cake layer). According to the model's concept, the mass of the detached sludge during the membrane backwashing is proportional to $C_{\mathrm{E}}$. Thus, a higher value of $C_{\mathrm{E}}$ indicates that a less thick the cake layer has accumulated on the membrane surface (i.e., thinner biological barrier), which produces a lower capability for retaining pollutant particles (i.e., biomass substrate) [30]. Such a circumstance leads to an increase of biomass substrate inside the MBR tank and consequently the mixed liquor recycled back from the MBR to the other tanks contains a higher biomass substrate mass, thus influencing the biological processes occurring inside the other tanks. In particular, the $\mathrm{CO}_{2}$ and $\mathrm{N}_{2} \mathrm{O}$ production process increases due to a higher biomass activity, conversely the higher availability of biomass substrate leads to a decrease of $\mathrm{CO}_{2}$ and $\mathrm{N}_{2} \mathrm{O}$.

A higher value of $C_{\mathrm{E}}$ also indicates a higher EQI value (as confirmed by the positive value of $\beta_{\mathrm{i}}$ for EQI) (Table 2 and Fig. 3a). The two most important model factors for EQI are $\mu_{\mathrm{PAO}}$ and $Y_{\mathrm{PAO}}$, which represent the maximum growth rate and the yield coefficient, respectively, of the PAOs. As confirmed by the negative value of $\beta_{\mathrm{i}}$ for $Y_{\mathrm{PAO}}$, this model factor has a negative effect on the EQI (Table 2 and Fig. 3a). An increasing $Y_{\text {PAO }}$ causes an increase in the pollutant removal in terms of COD and phosphate. Conversely, $\mu_{\mathrm{PAO}}$ has a positive effect on the EQI. In terms of the EQI, the key role of the effluent orthophosphate corresponds to the highest weighting factors. As shown in Table 2, the model factors related to the GHG prediction, unlike $\eta_{g 2}$, are non-influential in terms of the EQI.

This result corresponds with previous studies [11] for CAS systems and the model structure because the EQI assessment does not consider GHG emissions. This result suggests that in addition to the final aim of reducing the environmental impact of the MBR, the modeller should include the GHG contribution when computing the EQI. In terms of OC, the most important model factor is $C_{\mathrm{E}}$ (Table 2, Fig. $3 \mathrm{~b}$ ), which suggests that the membrane assumes a key role. As 
previously discussed, the value of $C_{\mathrm{E}}$ influences the quality of the effluent due to the higher or lower ability of the membrane cake layer to retain pollutants. Consequently, $C_{\mathrm{E}}$ is able to influence the cases in which $\left.C_{j}^{E F F}\right\rangle C_{L j}$. A higher value of $C_{\mathrm{E}}$ indicates a greater probability that $\left.C_{j}^{E F F}\right\rangle C_{L, j}$, and consequently, the EF value of OC increases.

In terms of $\mathrm{CO}_{2}$, the results show that the emission of $\mathrm{CO}_{2}$ is influenced by three biological model factors $\left(Y_{\mathrm{H}}, Y_{\mathrm{PAO}}\right.$ and $\left.b_{\mathrm{H}}\right)$ (Fig. $3 \mathrm{c}$ ) and two physical model factors $\left(f\right.$ and $C_{\mathrm{E}}$ ). The biological model factors show that the metabolic activity of heterotrophic biomass and the PAOs is relevant in terms of $\mathrm{CO}_{2}$ emissions. Specifically, when the PAO and the heterotrophic activity are higher, so are the $\mathrm{CO}_{2}$

Table 2

Results of the SRC application for the important model factors and each performance indicators (important model factors are underlined in grey); the sum of $\beta_{\mathrm{i}}^{2}$ is related to all model factors.

\begin{tabular}{|c|c|c|c|c|}
\hline $\begin{array}{l}R^{2} \\
\text { Symbol }\end{array}$ & $\begin{array}{l}\text { EQI } \\
0.88 \\
\beta_{\mathrm{i}}\end{array}$ & $\begin{array}{l}\text { OC } \\
0.96 \\
\beta_{\mathrm{i}}\end{array}$ & $\begin{array}{l}\mathrm{CO}_{2} \\
0.95 \\
\beta_{\mathrm{i}}\end{array}$ & $\begin{array}{l}\mathrm{N}_{2} \mathrm{O} \\
0.95 \\
\beta_{\mathrm{i}}\end{array}$ \\
\hline$Y_{\mathrm{H}}$ & -0.084 & 0.521 & 0.658 & 0.083 \\
\hline$Y_{\mathrm{PAO}}$ & -0.316 & 0.123 & 0.269 & 0.028 \\
\hline$Y_{\mathrm{PO} 4}$ & 0.113 & -0.077 & -0.058 & -0.045 \\
\hline$f_{\text {UAP }}$ & 0.022 & 0.076 & 0.063 & 0.1 \\
\hline$\eta_{\mathrm{y} \_ \text {PAO }}$ & -0.025 & 0.046 & 0.022 & -0.106 \\
\hline$Y_{\mathrm{AOB}}$ & -0.005 & -0.113 & -0.053 & -0.038 \\
\hline$\eta_{g_{2}}$ & -0.16 & -0.057 & -0.018 & -0.048 \\
\hline$\eta_{g_{3}}$ & -0.012 & 0.007 & 0.014 & 0.272 \\
\hline$\eta_{g_{4}}$ & 0.011 & -0.015 & -0.009 & 0.145 \\
\hline$q_{\mathrm{fe}}$ & -0.103 & -0.083 & -0.001 & -0.023 \\
\hline$b_{\mathrm{H}}$ & 0.155 & 0.253 & 0.167 & 0.187 \\
\hline$K_{\mathrm{O}_{2}, \mathrm{H}}$ & -0.063 & 0.001 & 0.002 & 0.355 \\
\hline$K_{\mathrm{NO}}$ & 0.021 & 0.014 & 0.016 & -0.153 \\
\hline $\mathrm{q}_{\mathrm{PP}}$ & -0.178 & 0.112 & 0.043 & 0.043 \\
\hline$K_{\mathrm{MAX}}$ & -0.16 & 0.003 & 0 & -0.001 \\
\hline$\mu_{\mathrm{PAO}}$ & 0.246 & -0.096 & -0.023 & -0.031 \\
\hline$f$ & 0.029 & -0.018 & -0.139 & -0.158 \\
\hline$C_{\mathrm{E}}$ & 0.731 & 0.707 & -0.573 & -0.646 \\
\hline$k_{L a \mathrm{~T}, 3}$ & -0.014 & 0 & -0.011 & -0.12 \\
\hline$F_{\mathrm{XH}}$ & -0.062 & -0.151 & -0.083 & -0.088 \\
\hline$\sum \beta_{i}^{2}$ & 0.88 & 0.98 & 0.93 & 0.85 \\
\hline
\end{tabular}

a

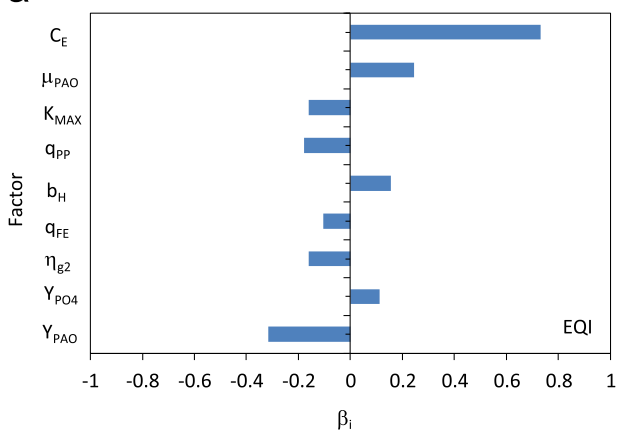

C

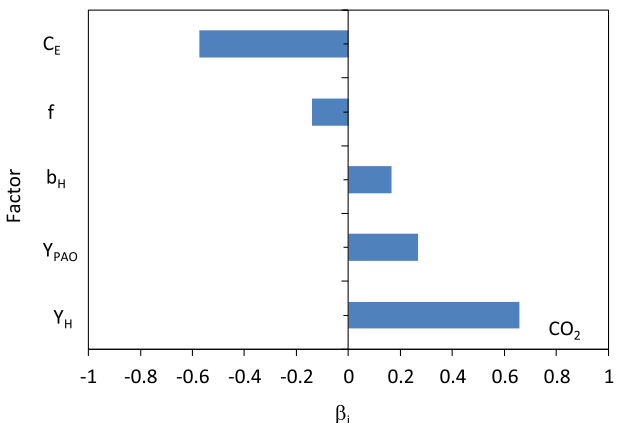

emissions, as confirmed by the positive values of $\beta_{i}$ for $Y_{\mathrm{PAO}}$ and $Y_{\mathrm{H}}$. The model factors $C_{\mathrm{E}}$ and $f$ (the latter represents the substrate fraction below the critical molecular weight that is retained by the membrane) have a negative effect on $\mathrm{CO}_{2}$, as confirmed by the $\beta_{i}$ values (Table 2). An increase in $f$ and $C_{\mathrm{E}}$ causes a decrease in the value of $\mathrm{CO}_{2}$. This result is primarily attributed to the ability of the model factors $f$ and $C_{\mathrm{E}}$ to control the substrate concentration inside the MBR tank and, consequently, the substrate recycled from the MBR tank to the aerobic tank. Such a result points out the crucial role played by the membrane in $\mathrm{CO}_{2}$ production and thus GHG emissions.

In terms of $\mathrm{N}_{2} \mathrm{O}$, a higher number of important model factors (namely, 10) were detected compared with the remaining performance indicators (Fig. 3d and Table 2). Among these important model factors, $C_{\mathrm{E}}$ and $K_{\mathrm{O} 2, \mathrm{H}}$ (half-saturation coefficient for $\mathrm{S}_{\mathrm{O} 2}$ related to the heterotrophic biomass) exhibited the highest influence on $\mathrm{N}_{2} \mathrm{O}$. The negative influences of $C_{\mathrm{E}}$ and $f\left(C_{\mathrm{E}}\right.$ and $f$ were higher, and $\mathrm{N}_{2} \mathrm{O}$ was lower) may be attributed to the lower substrate availability for the anoxic growth of the heterotrophic biomass (denitrification process), which causes an incomplete denitrification. The influence of $K_{\mathrm{O} 2, \mathrm{H}}$ and $K_{\mathrm{NO}}$ corroborates the findings in the literature, which indicate the high degree of uncertainty of the half-saturation coefficient related to the nitrogen transformation processes $[11,53]$. Note that the majority of the important model factors for $\mathrm{N}_{2} \mathrm{O}$ are directly related to the nitrogen transformation processes (namely, $\eta_{g 3}, \eta_{g 4}, \eta_{Y_{-} P A O}, K_{L a \mathrm{~T}, 3}$ and $K_{\mathrm{NO}}$ ). Among these model factors, $\eta_{\mathrm{g} 3}$ and $\eta_{g 4}$ are particularly interesting because these factors directly control the rate of the heterotrophic anoxic growth processes on $S_{\mathrm{F}}$ and $S_{\mathrm{A}}$ when $S_{\mathrm{NO}_{2}}$ is reduced to $S_{\mathrm{NO}}\left(\eta_{g 3}\right)$ and $S_{\mathrm{NO}}\left(\eta_{g 4}\right)$ is reduced to $S_{\mathrm{N}_{2} \mathrm{O}}$. This result corresponds with previous findings that identify nitrogen removal processes as some of the main sources of GHG uncertainty [11].

\subsection{The Extended-FAST results}

The application of the Extended-FAST method has been performed by considering only the 20 important model factors obtained using the SRC method. The Extended-FAST method has been performed by running 10,000 model simulations and

b

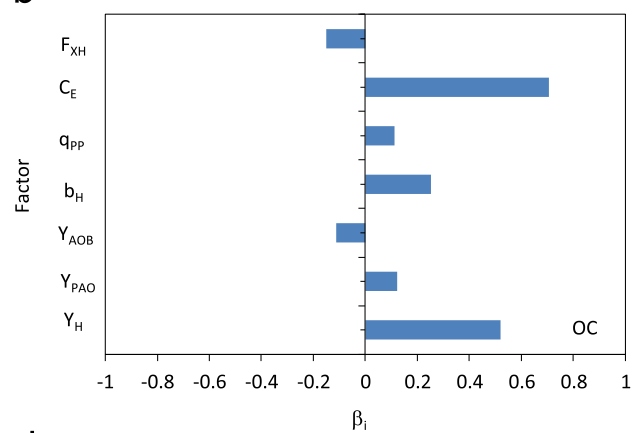

d

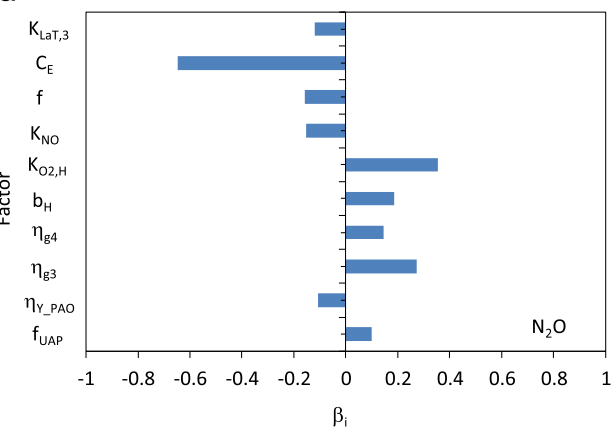

Fig. 3. Important model factors for $\mathrm{EQI}(\mathrm{a}), \mathrm{OC}(\mathrm{b}), \mathrm{CO}_{2}$ (c) and $\mathrm{N}_{2} \mathrm{O}$ (d). 
generating a model factor matrix with $\mathrm{NMC}=500$. The results for each model factor and performance indicator are summarised in Table 3 (the important model factors are underlined in light grey, and the interacting model factors are underlined in dark grey). Table 3 reveals that the sum of $S_{\mathrm{i}}$ explains $37 \%, 50 \%, 52 \%$ and $43 \%$ of the total variance for $\mathrm{EQI}, \mathrm{OC}, \mathrm{CO}_{2}$ and $\mathrm{N}_{2} \mathrm{O}$, respectively. These results indicate that a high interaction occurs among the model factors, as confirmed by the value of the sum of $S_{\mathrm{Ti}}$, which is always $>1$ (Table 3 ). This result corroborates the previous results obtained for CAS systems [11]. The high interaction among the model factors and the nonlinear behaviour obtained using the Extended-FAST application can be attributed to the significant reduction in the model factors (namely, less than $20 \%$ of the total model factors). The default or calibrated values of the remaining model factors (approximately 80\%) remain constant. The reduction in the number of uncertain model factors most likely increases the rate of factor interactions in terms of first-order and total-order effects.

Fig. 4 displays the results of the Extended-FAST application in terms of first-order and total-order effects. Among the 20 model factors considered during the application, only 12 model factors have been determined to be important or interacting for one of the three considered performance indicators. Fig. 4 reveals that the model factor $C_{\mathrm{E}}$ is important for all considered performance indicators and has the highest first-order and total-order effects, which corroborates the key role of the membrane in this context (i.e., GHG emissions and, overall, MBR performance). The EQI is sensitive to four model factors (namely, $C_{\mathrm{E}}, Y_{\mathrm{H}}, Y_{\mathrm{PAO}}$ and $K_{\mathrm{MAX}}$ ); the most important factor is $C_{\mathrm{E}}$, which contributes $22 \%$ of the total variance of the EQI (Fig. 4a and Table 3). The remaining three factors (i.e., $Y_{\mathrm{H}}, Y_{\mathrm{PAO}}$ and $K_{\mathrm{MAX}}$ ) are related to the biological activity of heterotrophic and PAO biomass (Fig. 4a and Table 3). All important model factors for the EQI, with the exception of $K_{\mathrm{MAX}}$, have also been selected as interacting model factors. Among the important factors, it is evident that $C_{\mathrm{E}}$ has the highest first-order and total-order effects, which suggests that $C_{\mathrm{E}}$ is also an interacting model factor for the EQI. Based on the results, it is evident that the total-order effect is high for some model factors related to aeration $\left(k_{\mathrm{LaT}, 3}\right.$ and $\left.K_{\mathrm{O} 2, \mathrm{H}}\right)$ and to PAO activity $\left(Y_{\mathrm{PAO}}, \mu_{\mathrm{PAO}}\right.$ and $\left.Y_{\mathrm{PO} 4}\right)$
(Fig. 4a and Table 3). These results emphasise that these model factors are also interacting; consequently, the modeller should not exclude their contribution to the total variance of the EQI.

In terms of OCs, the results demonstrate the importance of only two model factors $\left(Y_{\mathrm{H}}\right.$ and $C_{\mathrm{E}}$ ) (Fig. $4 \mathrm{~b}$ and Table 3). The influence of $Y_{\mathrm{H}}$ on $\mathrm{OC}$ is primarily related to the role of this factor in the SMP formation process. During the growth of the heterotrophic biomass, SMP is produced. Because the presence of SMP influences the total membrane resistance during the permeate extraction, the $\mathrm{OC}$ is influenced by $Y_{\mathrm{H}}$. As confirmed by Sweetapple et al. [11], the general effect of interacting model factors on OC uncertainty is negligible. With the exception of the important factors, none of the factors are determined to be interacting and should be analysed by the modeller.

According to Fig. $4 \mathrm{c}$ and Table $3, Y_{\mathrm{H}}$ and $C_{\mathrm{E}}$ are important, even for $\mathrm{CO}_{2}$, which corroborates the findings obtained with the SRC: the ability of these two factors to influence the substrate concentration inside the system and the $\mathrm{CO}_{2}$ production related to the biomass activity. Both $Y_{\mathrm{H}}$ and $C_{\mathrm{E}}$ exhibit the highest total effect on $\mathrm{CO}_{2}$, and $Y_{\mathrm{H}}$ and $C_{\mathrm{E}}$ have also been selected as interacting model factors. All other interacting model factors are related to PAO activity $\left(Y_{\mathrm{PAO}}\right.$ and $\left.Y_{\mathrm{PO} 4}\right)$. This result suggests that if the biological phosphorus removal process is considered, the effect of the PAO biomass activity on reducing $\mathrm{CO}_{2}$ emissions should be investigated.

In terms of $\mathrm{N}_{2} \mathrm{O}$, the factors $\eta_{g 3}, \eta_{g 4}, K_{\mathrm{O} 2, \mathrm{H}}$ and $C_{\mathrm{E}}$ exhibit the highest first-order effects. With the exception of $C_{\mathrm{E}}$, these model factors are directly related to the nitrogen transformation process. However, although the first-order effects of the important factors are significant, the variance in $\mathrm{N}_{2} \mathrm{O}$ is predominantly due to the interaction contribution. For $\mathrm{N}_{2} \mathrm{O}$, a considerable number of interacting factors were obtained (Fig. 4d). The interacting model factors are primarily related to the nitrogen transformation processes $\left(\eta_{g 3}\right.$ and $\left.\eta_{g 4}\right)$ and PAO activity $\left(q_{\mathrm{pp}}, q_{\mathrm{fe}}\right.$ and $\left.Y_{\mathrm{PO} 4}\right)$, which demonstrates the important role of the phosphorus removal processes, even for $\mathrm{N}_{2} \mathrm{O}$ emissions (Fig. 4d and Table 3).

\subsection{Uncertainty analysis results}

The uncertainty analysis has been performed by considering 12 model factors selected as important and interacting by means of

Table 3

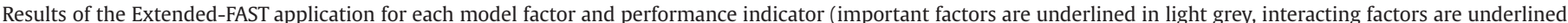
in dark grey).

\begin{tabular}{|c|c|c|c|c|c|c|c|c|c|c|c|c|c|c|c|c|}
\hline \multirow[b]{2}{*}{ Factor } & \multicolumn{4}{|l|}{ EQI } & \multicolumn{4}{|l|}{ OC } & \multicolumn{4}{|l|}{$\mathrm{CO}_{2}$} & \multicolumn{4}{|l|}{$\mathrm{N}_{2} \mathrm{O}$} \\
\hline & $S_{\mathrm{i}}$ & $S_{\mathrm{Ti}}$ & $S_{\mathrm{Ti}}-S_{\mathrm{i}}$ & $S_{\mathrm{Ni}}$ & $S_{\mathrm{i}}$ & $S_{\mathrm{Ti}}$ & $S_{\mathrm{Ti}}-S_{\mathrm{i}}$ & $S_{\mathrm{Ni}}$ & $S_{\mathrm{i}}$ & $S_{\mathrm{Ti}}$ & $S_{\mathrm{Ti}}-S_{\mathrm{i}}$ & $S_{\mathrm{Ni}}$ & $S_{\mathrm{i}}$ & $S_{\mathrm{Ti}}$ & $S_{\mathrm{Ti}}-S_{\mathrm{i}}$ & $S_{\mathrm{Ni}}$ \\
\hline$Y_{\mathrm{H}}$ & 0.051 & 0.143 & 0.091 & 0.269 & 0.023 & 0.091 & 0.068 & 0.207 & 0.366 & -0.7 & 0.334 & 0.722 & 0.002 & 0.058 & 0.056 & 0.159 \\
\hline$Y_{\mathrm{PAO}}$ & 0.03 & 0.223 & 0.193 & 0.569 & 0.002 & 0.047 & 0.046 & 0.138 & 0.014 & 0.189 & 0.175 & 0.379 & 0 & 0.029 & 0.029 & 0.083 \\
\hline$Y_{\mathrm{PO} 4}$ & 0.001 & 0.098 & 0.097 & 0.285 & 0 & 0.028 & 0.028 & 0.084 & 0.001 & 0.104 & 0.103 & 0.222 & 0.001 & 0.098 & 0.098 & 0.277 \\
\hline$f_{\text {UAP }}$ & 0.001 & 0.059 & 0.058 & 0.171 & 0.004 & 0.061 & 0.057 & 0.172 & 0 & 0.041 & 0.04 & 0.087 & 0 & 0.045 & 0.044 & 0.126 \\
\hline$\eta_{\mathrm{y} \_ \text {PAO }}$ & 0.001 & 0.028 & 0.027 & 0.078 & 0 & 0.021 & 0.021 & 0.063 & 0 & 0.036 & 0.036 & 0.078 & 0.001 & 0.035 & 0.034 & 0.098 \\
\hline$Y_{\mathrm{AOB}}$ & 0 & 0.064 & 0.064 & 0.188 & 0.001 & 0.062 & 0.061 & 0.186 & 0.001 & 0.042 & 0.042 & 0.09 & 0.001 & 0.046 & 0.046 & 0.13 \\
\hline$\eta_{g_{2}}$ & 0.006 & 0.031 & 0.025 & 0.073 & 0.001 & 0.015 & 0.014 & 0.043 & 0 & 0.014 & 0.014 & 0.03 & 0.004 & 0.025 & 0.021 & 0.059 \\
\hline$\eta_{g_{3}}$ & 0.002 & 0.052 & 0.05 & 0.148 & 0.001 & 0.064 & 0.063 & 0.193 & 0 & 0.021 & 0.021 & 0.046 & 0.045 & 0.143 & 0.098 & 0.277 \\
\hline$\eta_{g_{4}}$ & 0.001 & 0.036 & 0.035 & 0.104 & 0 & 0.013 & 0.013 & 0.038 & 0 & 0.015 & 0.015 & 0.031 & 0.022 & 0.15 & 0.128 & 0.363 \\
\hline$q_{\mathrm{fe}}$ & 0.002 & 0.062 & 0.059 & 0.175 & 0.001 & 0.063 & 0.062 & 0.187 & 0.001 & 0.04 & 0.039 & 0.085 & 0.004 & 0.096 & 0.092 & 0.261 \\
\hline$b_{\mathrm{H}}$ & 0.002 & 0.025 & 0.023 & 0.067 & 0.006 & 0.028 & 0.022 & 0.068 & 0.013 & 0.042 & 0.029 & 0.062 & 0.011 & 0.076 & 0.065 & 0.184 \\
\hline$K_{\mathrm{O}_{2}, \mathrm{H}}$ & 0.001 & 0.07 & 0.068 & 0.201 & 0.001 & 0.065 & 0.064 & 0.195 & 0 & 0.031 & 0.031 & 0.067 & 0.077 & 0.162 & 0.085 & 0.241 \\
\hline$K_{\mathrm{NO}}$ & 0 & 0.027 & 0.027 & 0.079 & 0 & 0.025 & 0.025 & 0.075 & 0 & 0.036 & 0.035 & 0.077 & 0.016 & 0.082 & 0.066 & 0.188 \\
\hline $\mathrm{q}_{\mathrm{PP}}$ & 0.011 & 0.084 & 0.073 & 0.215 & 0.001 & 0.05 & 0.049 & 0.148 & 0.001 & 0.017 & 0.016 & 0.035 & 0.005 & 0.134 & 0.129 & 0.366 \\
\hline$K_{\mathrm{MAX}}$ & 0.021 & 0.083 & 0.061 & 0.18 & 0.001 & 0.036 & 0.035 & 0.106 & 0 & 0.009 & 0.009 & 0.02 & 0.011 & 0.063 & 0.052 & 0.147 \\
\hline$\mu_{\mathrm{PAO}}$ & 0.012 & 0.094 & 0.082 & 0.242 & 0.001 & 0.031 & 0.03 & 0.092 & 0.001 & 0.04 & 0.04 & 0.086 & 0.002 & 0.048 & 0.046 & 0.131 \\
\hline$f$ & 0.003 & 0.061 & 0.058 & 0.17 & 0.001 & 0.051 & 0.049 & 0.149 & 0.003 & 0.024 & 0.021 & 0.046 & 0.005 & 0.021 & 0.017 & 0.048 \\
\hline$C_{\mathrm{E}}$ & 0.223 & 0.563 & 0.34 & 1 & 0.454 & 0.783 & 0.329 & 1 & 0.112 & 0.574 & 0.462 & 1 & 0.205 & 0.557 & 0.352 & 1 \\
\hline$k_{L a \mathrm{~T}, 3}$ & 0.002 & 0.087 & 0.084 & 0.249 & 0.001 & 0.056 & 0.056 & 0.169 & 0.001 & 0.042 & 0.042 & 0.09 & 0.016 & 0.087 & 0.071 & 0.201 \\
\hline$F_{\mathrm{XH}}$ & 0.001 & 0.034 & 0.033 & 0.097 & 0.001 & 0.038 & 0.037 & 0.113 & 0.002 & 0.025 & 0.023 & 0.05 & 0.002 & 0.039 & 0.037 & 0.105 \\
\hline$\Sigma S_{\mathrm{i}}$ & 0.373 & - & - & - & 0.5 & - & - & - & 0.517 & - & - & - & 0.429 & - & - & - \\
\hline$\Sigma S_{\mathrm{Ti}}$ & - & 1.922 & - & - & - & 1.628 & - & - & - & 2.042 & - & - & - & 1.994 & - & - \\
\hline
\end{tabular}


a

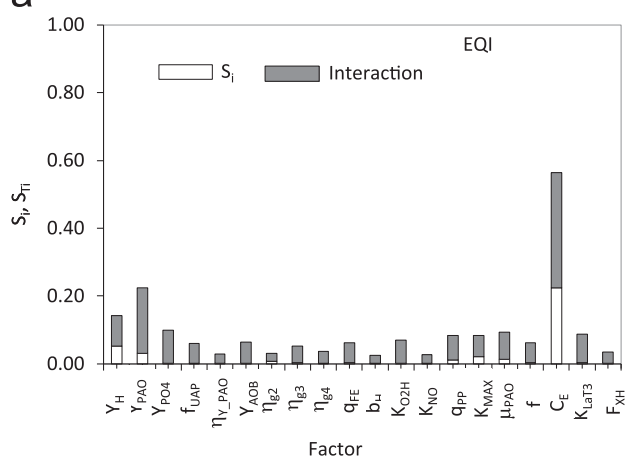

C

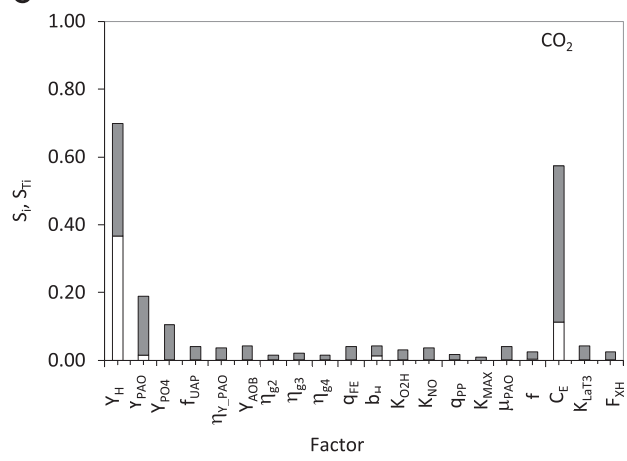

b

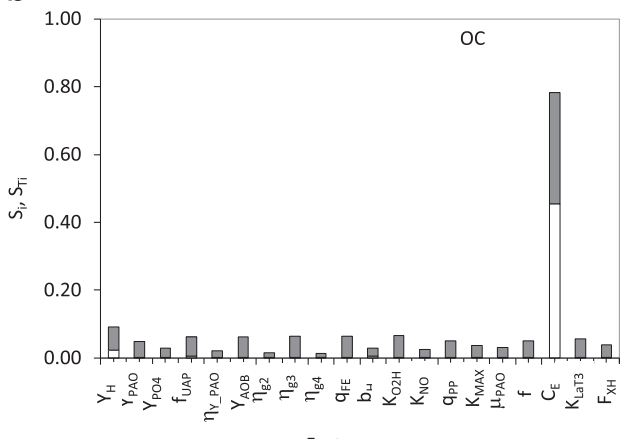

Factor

d

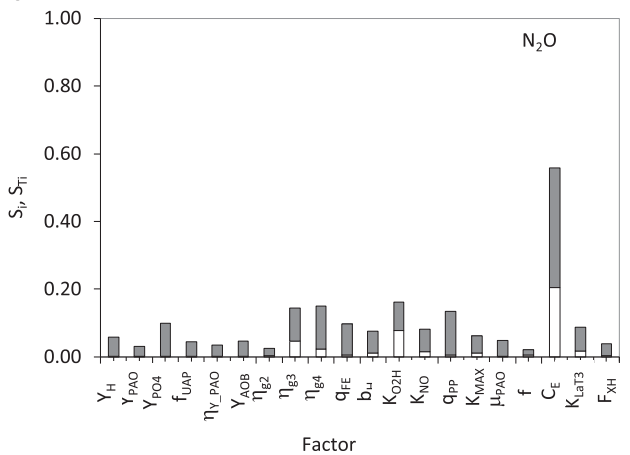

Fig. 4. Important model factors for $\mathrm{EQI}(\mathrm{a}), \mathrm{OC}(\mathrm{b}), \mathrm{CO}_{2}$ (c) and $\mathrm{N}_{2} \mathrm{O}$ (d).

a

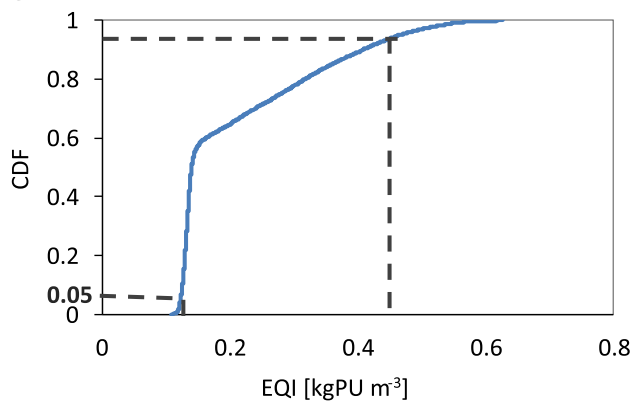

C

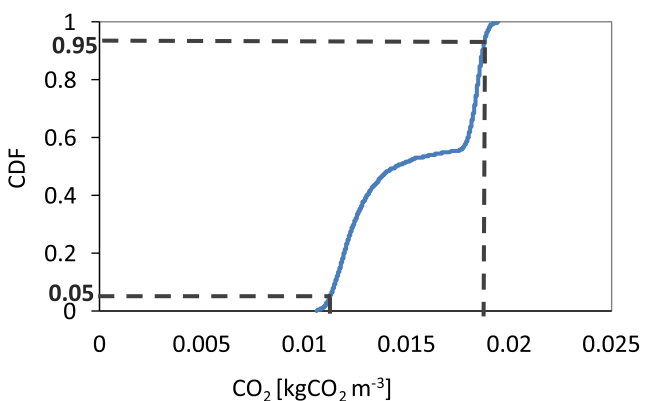

b

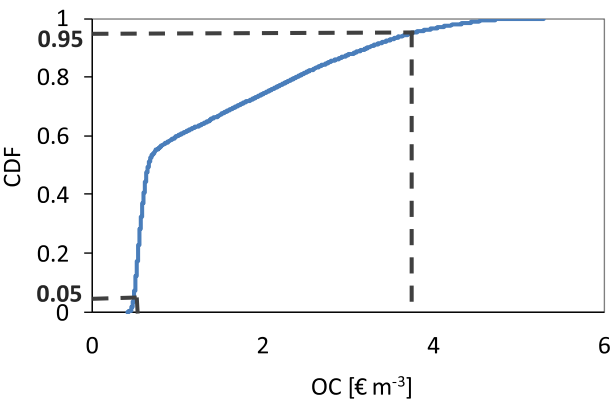

d

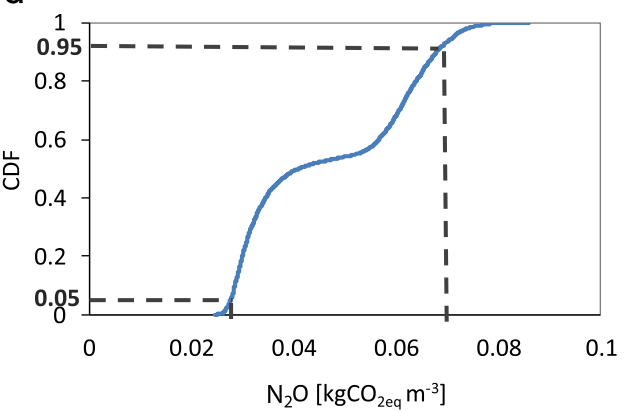

Fig. 5. $\mathrm{CDF}$ for $\mathrm{EQI}(\mathrm{a}), \mathrm{OC}(\mathrm{b}), \mathrm{CO}_{2}$ (c) and $\mathrm{N}_{2} \mathrm{O}$ (d).

the Extended-FAST method. Considering the propagation of the uncertainty in the 12 model factors, the same range of variation factor that was applied during the SRC and Extended-FAST application was employed. The uncertainty analysis has been applied by running 7100 model simulations.

In Fig. 5, the CDFs (expressed per $\mathrm{m}^{3}$ of treated permeate) for the 5th and 95th percentiles are shown. The cumulative distribution of the EQIs shows that the uncertainty in the model prediction ranges between 0.12 and $0.46 \mathrm{~kg} \mathrm{PU} \mathrm{m}^{-3}$ (5th and 95th percentiles, respectively). In terms of $\mathrm{OC}$, the range of the uncertainty in the model prediction varies between 0.44 and $3.75 € \mathrm{~m}^{-3}$ (5th and 95th percentiles, respectively). The cumulative distributions for the EQI and OC (Figs. 5a and b) exhibit discontinuities, which indicates that the EQI and the OC remain approximately constant $\left(0.14 \mathrm{~kg} \mathrm{PU} \mathrm{m}^{-3}\right.$ and $0.66 € \mathrm{~m}^{-3}$, respectively) for approximately $53 \%$ of the simulated values. These results show that by varying the 12 uncertain model 
factors, the EQI and OC values are certain for approximately 53\% of the cases. Conversely, the cumulative distributions of the GHG performance indicators (Figs. $5 \mathrm{c}$ and d) exhibit a different pattern. A high variability of $\mathrm{CO}_{2}$ and $\mathrm{N}_{2} \mathrm{O}$ in terms of $\mathrm{CDF}$ is shown (Figs. $5 \mathrm{c}$ and $\mathrm{d}$ ). Therefore, the effect of the uncertainty in the 12 explored model factors exhibits a higher influence for predicting the GHGs compared with the OC or the EQI. This result suggests that the modeller can neglect the model factors that are determined to be important or interacting only for OC and EQI when ones aim is to quantify the uncertainty in the GHGs. However, the CDF of $\mathrm{N}_{2} \mathrm{O}$ shows a higher uncertainty than does the $\mathrm{CDF}$ of $\mathrm{CO}_{2}$, as suggested by the extensive uncertainty between the 5th and 95th percentiles (Figs. $5 \mathrm{c}$ and d). The uncertainty in the model prediction for $\mathrm{CO}_{2}$ varies between 0.011 and $0.019 \mathrm{~kg} \mathrm{CO}_{2} \mathrm{~m}^{-3}$ (5th and 95th percentiles, respectively), whereas the uncertainty in the model prediction for $\mathrm{N}_{2} \mathrm{O}$ varies between 0.027 and $0.071 \mathrm{~kg} \mathrm{CO}_{2 \mathrm{eq}} \mathrm{m}^{-3}$. The $\mathrm{CDF}$ of $\mathrm{CO}_{2}$ shows that in approximately $44 \%$ of the cases, approximately $0.018 \mathrm{kgCO}_{2} \mathrm{~m}^{-3}$ of $\mathrm{CO}_{2}$ is maintained. This result suggests that to improve the total GHG prediction, the modeller should consider the model factors that are directly related to $\mathrm{N}_{2} \mathrm{O}$ modelling. The uncertainty in $\mathrm{N}_{2} \mathrm{O}$, which is expressed as a percentage of the $\mathrm{N}_{2} \mathrm{O}$ emitted with respect to the influent nitrogen load, is $0.17 \%$. This latter value corresponds to the difference in the emission factors computed for the 95th and 5th percentiles of the CDF of $\mathrm{N}_{2} \mathrm{O}$. The emission factors of $\mathrm{N}_{2} \mathrm{O}$ are $0.11 \%$ and $0.28 \%$ for the 5 th and 95 th percentiles, respectively. The resulting emission factors of $\mathrm{N}_{2} \mathrm{O}$, in order of magnitude, correspond with the measured emission factors for MBR in France (0.1-0.2\%) [8].

The uncertainty in the prediction of $\mathrm{CO}_{2}$, which is expressed as a percentage of $\mathrm{CO}_{2}$ emitted with respect to the influent $\mathrm{BOD}_{5}$ load, is $2.2 \%$. This latter value corresponds to the difference in the emission factors computed for the 95th and 5th percentiles of the $\mathrm{CDF}$ of $\mathrm{CO}_{2}$. The emission factors of $\mathrm{CO}_{2}$ are $3.1 \%$ and $5.3 \%$ (5th and 95th percentiles, respectively).

The derived results provide a valuable indication of the degree of uncertainty for both the $\mathrm{N}_{2} \mathrm{O}$ and the $\mathrm{CO}_{2}$ model predictions for MBR systems.

\section{Conclusions}

The key findings of this study are summarised as follows:

- The GSA reveals that the membrane has a key role in GHG emissions. In particular, some physical model factors related to the membrane exhibit a significant impact on the total performance indicators (namely, efficiency of backwashing $C_{\mathrm{E}}$ ). Indeed, $C_{\mathrm{E}}$ controls the mass of substrate retained by the membrane and, thus, the biological process in the MBR.

- The Extended-FAST application reveals that model factors of the nitrogen transformation processes (namely, $\eta_{g 3}$ and $\eta_{g 4}$ ) and PAO activity (namely, $q_{\mathrm{pp}}, q_{\mathrm{fe}}$ and $Y_{\mathrm{PO} 4}$ ) are affected by a high degree of interaction. To reduce the uncertainty in the $\mathrm{N}_{2} \mathrm{O}$ estimation, a careful assessment of their values is advisable.

- Model factors related to the prediction of GHGs are noninfluential in terms of the EQI, which suggests that including GHG terms in the EQI expression should improve the total environmental impact of the MBR system.

- The uncertainty in the emission factors for $\mathrm{CO}_{2}$ is higher than the uncertainty in the emission factors for $\mathrm{N}_{2} \mathrm{O}$ (namely, $2.2 \%$ and $0.17 \%$, respectively).

Overall, this study allowed us to gain insights into the key model factors which influence the most the GHG emissions. In the future, the efforts should be provided in the assessment of those model factors as well as processes in order to enhance the GHGs assessment. With this regard, the use of measured GHG data will improve both the processes knowledge and the model results.

\section{Acknowledgements}

This work forms part of a research project supported by grant of the Italian Ministry of Education, University and Research (MIUR) through the Research project of national interest PRIN2012 (D.M. 28 dicembre 2012 n. 957/Ric - Prot. 2012PTZAMC) entitled "Energy consumption and GreenHouse Gas (GHG) emissions in the wastewater treatment plants: a decision support system for planning and management - http://ghgfromwwtp.unipa.it" in which the corresponding author is the Principal Investigator.

\section{Appendix A. Supporting information}

Supplementary data associated with this article can be found in the online version at http://dx.doi.org/10.1016/j.memsci.2014.10.008.

\section{References}

[1] M.J. Kampschreur, H. Temmink, R. Kleerebezem, M.S.M. Jettena, M.C.M. van Loosdrecht, Nitrous oxide emission during wastewater treatment, Water Res. 43 (2009) 4093-4103.

[2] X. Flores-Alsina, L. Corominas, L. Snip, P.A. Vanrolleghem, Including greenhouse gas emissions during benchmarking of wastewater treatment plant control strategies, Water Res. 45 (2011) 4700-4710.

[3] L. Corominas, X. Flores-Alsina, L. Snip, P.A. Vanrolleghem, Comparison of different modeling approaches to better evaluate greenhouse gas emissions from whole wastewater treatment plants, Biotechnol. Bioeng. 109 (11) (2012) 2854-2863.

[4] Y. Law, L. Ye, Y. Pan, Z. Yuan, Nitrous oxide emissions from wastewater treatment processes, Philos. Trans. R. Soc. B 367 (2012) 1265-1277.

[5] IPCC, Climate change 1995: the science of climate change, in: J.T. Houghton, L.G. Meira Filho, B.A. Callander, N. Harris, A. Kattenberg, K. Maskell (Eds.), Intergovernmental Panel on Climate Change, Cambridge University Press, Cambridge, United Kingdom, 1996.

[6] J. Foley, D. de Haas, Z. Yuan, P. Lant, Nitrous oxide generation in full-scale biological nutrient removal wastewater treatment plants, Water Res. 44 (2010) $831-844$

[7] Z. Hu, J. Zhang, S. Li, H. Xie, J. Wang, T. Zhang, Y. Li, H. Zhang, Effect of aeration rate on the emission of $\mathrm{N}_{2} \mathrm{O}$ in anoxic-aerobic sequencing batch reactors ( $\mathrm{A} / \mathrm{O}$ SBRs), J. Biosci. Bioeng. 109 (5) (2010) 487-491.

[8] GWRC - Global Water Research Coalition. $\mathrm{N}_{2} \mathrm{O}$ and $\mathrm{CH}_{4}$ Emission from Wastewater Collection and Treatment Systems - State of the Science Report, 2011-29, London, UK.

[9] M.R.J. Daelman, E.M. van Voorthuizen, U.G.J.M. van Dongen, E.I.P. Volcke, M.C. M. van Loosdrecht, Methane emission during municipal wastewater treatment, Water Res. 46 (2012) 3657-3670.

[10] L. Guo, P.A. Vanrolleghem, Calibration and validation of an activated sludge model for greenhouse gases no. 1 (ASMG1): prediction of temperature dependent $\mathrm{N}_{2} \mathrm{O}$ emission dynamics, Bioprocess Biosyst. Eng. 37 (2014) 151-163.

[11] C. Sweetapple, G. Fu, D. Butler, Identifying key sources of uncertainty in the modelling of greenhouse gas emissions from wastewater treatment, Water Res. 47 (2013) 4652-4665.

[12] H.D. Monteith, H.R. Sahely, H.L. MacLean, D.M. Bagley, A rational procedure for estimation of greenhouse-gas emissions from municipal wastewater treatment plants, Water Environ. Res. 77 (2005) 390-403.

[13] W.C. Hiatt, C.P.L. Grady Jr., An updated process model for carbon oxidation, nitrification, and denitrification, Water Environ. Res. 80 (2008) 2145-2156.

[14] R., Gori, D., Rosso, C., Lubello, 2010 Carbon footprint and energy footprint of activated sludge wastewater treatment plants. In: Proceeding of the Venice 2010 Third International Symposium on Energy from Biomass and Waste Venice, Italy; 8-11 November 2010.

[15] B.J. Ni, M. Ruscalleda, C. Pellicer-Nàcher, B.F. Smets, Modeling nitrous oxide production during biological nitrogen removal via nitrification and denitrification: extensions to the general ASM models, Environ. Sci. Technol. 45 (2011) 7768-7776.

[16] IPCC, 2006 Guidelines for national greenhouse gas inventories. Intergovernmental Panel on Climate Change. Available at: 〈http://www.ipcc-nggip.iges.or. jp/public/2006gl/index.html>.

[17] (Available at:) Changes in atmospheric constituents and in radiative forcing, Intergovernmental Panel on Climate Change, 2007 (Fourth Assessment Report (AR4), Chapter 2). 
[18] M.B. Shahabadi, L. Yerushalmi, F. Haghighat, Impact of process design on greenhouse gas (GHG) generation by wastewater treatment plants, Water Res. 43 (10) (2009) 2679-2687.

[19] B.J. Ni, Z. Yuan, K. Chandran, P.A. Vanrolleghem, S. Murthy, Evaluating four mathematical models for nitrous oxide production by autotrophic ammoniaoxidizing bacteria, Biotechnol. Bioeng. 110 (1) (2013) 153-163.

[20] B.J. Ni, L. Ye, Y. Law, C. Byers, Z. Yuan, Mathematical modeling of nitrous oxide $\left(\mathrm{N}_{2} \mathrm{O}\right)$ emissions from full-scale wastewater treatment plants, Environ. Sci. Technol. 47 (14) (2013) 7795-7803.

[21] Y. Tang, P. Reed, K. van Werkhoven, T. Wagener, Advancing the identification and evaluation of distributed rainfall-runoff models using global sensitivity analysis, Water Resour. Res. 43 (2007) 6.

[22] C.B.S. Dotto, G. Mannina, M. Kleidorfer, L. Vezzaro, M. Henrichs, D.T. McCarthy, G. Freni, W. Rauch, A. Deletic, Comparison of different uncertainty techniques in urban stormwater quantity and quality modelling, Water Res. 46 (8) (2012) $2545-2558$.

[23] L. Benedetti, F. Claeys, I. Nopens, P.A. Vanrolleghem, Assessing the convergence of LHS Monte Carlo simulations of wastewater treatment models, Water Sci. Technol. 63 (10) (2011) 2219-2224.

[24] A. Cosenza, G. Mannina, M.B. Neumann, G. Viviani, P.A. Vanrolleghem, Biological nitrogen and phosphorus removal in membrane bioreactors: model development and parameter estimation, Bioprocess Biosyst. Eng. 36 (2013) 499-514.

[25] T. Jiang, S. Myngheer, D.J.W. De Pauw, H. Spanjers, I. Nopens, M.D. Kennedy, $G$ Amy, P.A. Vanrolleghem, Modelling the production and degradation of soluble microbial products (SMP) in membrane bioreactors (MBR), Water Res. 42 (20) (2008) 4955-4964.

[26] G., Pujol 2007. Sensitivity: sensitivity Analysis, R package version 1.3-0.

[27] G. Munz, R. Gori, L. Cammilli, C. Lubello, Characterization of tannery wastewater and biomass in a membrane bioreactor using respirometric analysis, Bioresour. Technol. 99 (2008) 8612-8618.

[28] A. Saltelli, S. Tarantola, F. Campolongo, M. Ratto, Sensitivity analysis in practice. A guide to assessing scientific models, Probability and Statistics Series, John Wiley \& Sons Publishers, Chichester, England, 2004.

[29] S. Judd, A review of fouling of membrane bioreactors in sewage treatment, Water Sci. Technol. 49 (2004) 229-235

[30] G. Mannina, G. Di Bella, G. Viviani, An integrated model for biological and physical process simulation in membrane bioreactors (MBR), J. Membr. Sci. $376(1-2)$ (2011) 56-69.

[31] M. Henze, W. Gujer, T. Mino, M.C.M. van Loosdrecht, Activated sludge models ASM1, ASM2, ASM2d and ASM3, IWA task group on mathematical modelling for design and operation of biological wastewater treatment, IWA Publishing, London, 2000.

[32] P.A. Vanrolleghem, C. Rosen, U. Zaher, J. Copp, L. Benedetti, E. Ayesa, Ulf Jeppsson, Continuity-based interfacing of models for wastewater systems described by Petersen matrices, Water Sci. Technol. 52 (2005) 493-500.

[33] H. Hauduc, L. Rieger, I. Takács, A. Héduit, P.A. Vanrolleghem, S. Gillot, A systematic approach for model verification: application on seven published activated sludge models, Water Sci. Technol. 61 (2010) 825-839.

[34] L., Snip, 2010 Quantifying the greenhouse gas emissions of wastewater treatment plants (Master thesis).

[35] APHA, AWWA, WEF, Standard Methods for the Examination of Water and Wastewater, 20th ed., American Public Health Association/American Water
Works Association/Water Environment Federation, Washington, DC, USA, 1998.

[36] A. Cosenza, G. Di Bella, G. Mannina, M. Torregrossa, The role of EPS in fouling and foaming phenomena for a membrane bioreactor, J. Bioresour. Technol. 147 (2013) 184-192.

[37] U. Jeppsson, M.N. Pons, I. Nopens, J. Alex, J.B. Copp, K.V. Gernaey, C. Rosen, J.P. Steyer, P.A. Vanrolleghem, Benchmark simulation model no 2: general protocol and exploratory case studies, Water Sci. Technol. 56 (8) (2007) 67-78.

[38] G. Mannina, A. Cosenza, The fouling phenomenon in membrane bioreactors: assessment of different strategies for energy saving, J. Membr. Sci. 444 (2013) 332-344.

[39] P.A. Vanrolleghem, S. Gillot, Robustness and economic measures as control benchmark performance criteria, Water Sci. Technol. 45 (4-5) (2002) 117-126.

[40] M.L. Davis, Water and Wastewater Engineering: Design Principles and Practice, McGraw-Hill, New York, 2010.

[41] S.J. Judd, C. Judd, Principles and Applications of Membrane Bioreactors in Water and Wastewater Treatment, Second edition, Elsevier, London, UK, 2010.

[42] P.A. Vanrolleghem, U. Jeppsson, J. Carstensen, B. Carlsson, G. Olsson, Integration of wastewater treatment plant design and operation-a systematic approach using cost functions, Water Sci. Technol. 34 (3-4) (1996) 159-171.

[43] A. Stare, D. Vrecko, N. Hvala, S. Strmcnik, Comparison of control strategies for nitrogen removal in an activated sludge process in terms of operating costs, Water Res. 41 (9) (2007) 2004-2014.

[44] J. Cariboni, D. Gatelli, R. Liska, A. Saltelli, The role of sensitivity analysis in ecological modelling, Ecol. Model. 203 (1-2) (2007) 167-182.

[45] P. Moreau, V. Viaud, V. Parnaudeau, J. Salmon-Monviola, P. Durand, An approach for global sensitivity analysis of a complex environmental model to spatial inputs and parameters: a case study of an agro-hydrological model, Environ. Model. Softw. 47 (2013) 74-87.

[46] M.B. Neumann, Comparison of sensitivity analysis techniques for modelling micropollutant oxidation in water treatment, Sci. Total Environ. 433 (1) (2012) $530-537$.

[47] A. Saltelli, M. Ratto, S. Tarantola, F. Campolongo, Sensitivity analysis for chemical models, Chem. Rev. 105 (2005) 2811-2827.

[48] G. Sin, K.V. Gernaey, M.B. Neumann, M.C.M. van Loosdrecht, W. Gujer Uncertainty analysis in WWTPmodel applications: a critical discussion using an example from design, Water Res. 43 (11) (2009) 2894-2906.

[49] M.D. McKay, R.J. Beckman, W.J. Conover, A comparison of three methods for selecting values of input variables in the analysis of output from a computer code, Technometrics 21 (2) (1979) 239-245.

[50] D. Kaelin, R. Manser, L. Rieger, J. Eugster, K. Rottermann, H. Siegrist, Extension of ASM3 for two-step nitrification and denitrification and its calibration and validation with batch tests and pilot scale data, Water Res. 43 (2009) 1680-1692.

[51] G. Mannina, G. Viviani, Hybrid moving bed biofilm reactors: an effective solution for upgrading a large wastewater treatment plant, Water Sci. Technol. 60 (5) (2009) 1103-1116.

[52] G. Mannina, G. Viviani, Separate and combined sewer systems: a long-term modelling approach, Water Sci. Technol. 60 (3) (2009) 555-565.

[53] P. Reichert, P. Vanrolleghem, Identifiability and uncertainty analysis of the river water quality model no. 1 (RWQM1), Water Sci. Technol. 43 (7) (2001) 329-338. 